\title{
Identificação de Mecanismos de Controle em Alianças Estratégicas para Desenvolvimento Tecnológico: um Estudo Múltiplo de Casos no Setor Metal-mecânico ao longo das Fases do Relacionamento
}

\author{
Carlos Gabriel Eggert Boehs \\ Andréa Paula Segatto-Mendes
}

\begin{abstract}
RESUMO
As atividades de pesquisa e desenvolvimento compreendem processos com níveis crescentes de complexidade. Nesse contexto, empresas que identificam o capital tecnológico como fonte de diferencial competitivo demandam recursos e competências, que nem sempre se encontram disponíveis em seu ambiente interno, assim elas utilizam-se de relações de cooperação que compreendem níveis de interação de objetivos, estruturas, processos e indivíduos com características particulares. A presente pesquisa, a partir dos estudos de relacionamentos interorganizacionais, tem como propósito a identificação de mecanismos de controle em alianças estratégicas voltadas para atividades de desenvolvimento tecnológico entre empresas. O trabalho apresenta uma revisão teórica referente a relacionamentos interorganizacionais do tipo alianças estratégicas e conceitos referentes ao desenvolvimento tecnológico conjunto. A metodologia utilizada foi a do estudo de casos múltiplos, com a análise de três alianças entre empresas do setor metal-mecânico com atividades de desenvolvimento tecnológico comprovadas. Assim adotou-se um modelo de pesquisa empírica que considera a perspectiva dinâmica e processual do relacionamento interorganizacional compreendida por meio de fases do relacionamento. Os resultados obtidos foram a identificação de mecanismos de controle adotados ao longo das fases de interação de cooperação tecnológica das empresas por meio de alianças estratégicas, assim como a abrangência, foco e fatores influenciadores na adoção desses mecanismos.
\end{abstract}

Palavras-chave: alianças tecnológicas estratégicas; mecanismos de controle; monitoramento, fases do relacionamento.

\begin{abstract}
The activities of research and development are caracterized by ascendent levels of complexity. Companies that consider technological resources as their source of competitive advantage demand proportional levels of competences that cannot be always developed on their internal structure. Considering a situation which brings together objectives, structures, processes and individuals, these relations of cooperation bring relevant challenges of administration to executives and to organizational and strategical studies. This research has the purpose of identifying mechanisms of control in strategical alliances oriented to technological development activities. A theorical reference about strategical alliances, bringing the focus to instruments of coordination of formal and informal control in cooperated activities. The methodology has adopted the strategy of multiple case study, by which three alliances of the metal-mechanic sector have been analyzed. The study adopts a model that considers the processual dimension of interorganizational relations in order to identify the mechanisms of control in each stage of the relationship. The study intends to identify elements that influence the determination of these mechanisms of control so that may be possible to contribute with future studies about the coordination of strategical alliances.
\end{abstract}

Key words: strategical technological alliances; mechanisms of control; stages of relationship. 


\section{INTRODUÇÃO}

O desenvolvimento tecnológico que se caracteriza por crescente complexidade demanda acesso a informações privilegiadas nos setores em que o processo de inovação se torna a principal arma competitiva. A estrutura das indústrias passa a ser influenciada por uma "teia complexa de alianças" (Castells, 2003, p. 220) entre empresas. Nesse sentido, a compreensão dos instrumentos de coordenação destas relações de cooperação para o desenvolvimento tecnológico aponta uma preocupação crescente a respeito dos processos enfrentados pelas organizações na sua relação com o meio e para a efetividade das atividades de desenvolvimento tecnológico das empresas. De acordo com Hall (2004), as alianças estratégicas, entre elas as relações voltadas para atividades de desenvolvimento tecnológico, compreendem determinados fluxos de recursos, denominados programas conjuntos, que abrangem não apenas relações de interdependência, mas também ações de cooperação que se podem estender profundamente e para mais de uma área específica.

As alianças também podem ser compreendidas por meio de um conjunto de etapas ou processos cíclicos ou seqüenciais, abrangendo a construção do relacionamento, sua manutenção e ampliação das transações entre as partes, até o seu eventual encerramento. A compreensão das alianças, sob esse enfoque dinâmico, passa a apresentar sua relevância, quando consideramos que não apenas aspectos estruturais, mas também processuais, determinam as condições do relacionamento entre as empresas parceiras de uma aliança estratégica. Este trabalho, portanto, se propôs a analisar mecanismos de controle em casos de alianças estratégicas voltadas para atividades de desenvolvimento tecnológico, sob o prisma dos processos de relacionamentos interorganizacionais, abrangendo as etapas de caráter cíclico, que envolvem a negociação, o compromisso e a execução de atividades. A preocupação do estudo, portanto, está concentrada na dinâmica processual das relações voltadas para atividades de desenvolvimento tecnológico para que, em estudos futuros, se possa buscar compreender também sua relação com possíveis resultados de atividades de caráter tecnológico e inovação.

\section{REVISÃo TEÓRICA}

\section{Alianças Estratégicas}

No contexto mais amplo dos estudos organizacionais, as alianças são 
identificadas como relacionamentos interorganizacionais específicos. Hall (2004) compreende que programas conjuntos, joint-ventures e alianças estratégicas podem ser conceituados como um tipo especial de fluxos de recursos, em que não há apenas relações de interdependência de recursos, mas também ações de cooperação, que se podem estender profundamente e para mais de uma área específica. Estas relações são verificáveis, por exemplo, em processos de cooperação para pesquisa e desenvolvimento, podendo constituir interações intencionais e não apenas resposta à pressão ambiental.

Segundo Child (1999), as alianças emergem sob a forma de joint-ventures, arranjos livremente constituídos como consórcios e colaborações, ou ainda sob a forma da integração total, por meio de fusões. De outro lado, segundo Hagedoorn (1990), há formas sem participação acionária, com base em acordos contratuais entre os parceiros. Nesse grupo encontram-se, entre outros, acordos de desenvolvimento conjunto de produtos, pactos de pesquisa conjunta, acordos mútuos de licenciamento e contratos de Pesquisa e Desenvolvimento (P\&D). Segundo Klotzle (2002), no contexto das atividades de pesquisa e desenvolvimento, as empresas passam a adotar cada vez mais acordos de parceria para realizarem este tipo de atividade que, tradicionalmente, foi muito vigiado pelas empresas. Estas não apenas estão investindo em pesquisa e desenvolvimento por meio de parcerias, como estão fazendo esses investimentos em conjunto com empresas de outros países e, muitas vezes, dentro de localidades estrangeiras.

\section{Atividades de Desenvolvimento Tecnológico e Alianças Tecnológicas}

Segundo Rodrigues e Carvalho (1991), a tecnologia tem a característica de ser um bem intangível. Neste caso, a transferência processada no ato de comercialização é a transferência de conhecimento, que pode estar registrada em documentos escritos ou na mente das pessoas. Segundo o entendimento da Baêta e Silva (2002), a tecnologia apresenta um conjunto amplo de finalidades: métodos para transformar inputs em outputs; aplicação dos resultados de pesquisa científica à produção de bens e serviços; tipo específico de conhecimento, processo ou técnica exigido para fins práticos; conhecimentos de que uma sociedade dispõe sobre ciências e artes industriais, incluindo os fenômenos sociais e físicos, e sua aplicação à produção de bens e serviços. O processo de gestão da tecnologia compreende estratégias de utilização de técnicas de administração com a finalidade de maximizar o potencial tecnológico da empresa, seja por meio da provisão de ambientes internos para realização de atividades de pesquisa e desenvolvimento, seja mediante aquisições externas.

A cooperação tecnológica entre organizações também pode ser adotada para 
fins de aquisição e/ou desenvolvimento, de forma que ocorra cooperação com outras empresas e instituições de ensino e pesquisa para o desenvolvimento de produtos e processos, quando a tecnologia usada não pode ser efetivamente transferida por meio da venda do direito de utilização ou da simples transferência de informações. A cooperação pode ainda contar com a ação de um Gatekeeper, que consiste em que uma pessoa, responsável pela manutenção da rede de contato, que atua dentro e fora da empresa, identifica ofertas tecnológicas disponíveis no mercado e as canaliza para os objetivos da empresa. Sua atuação pode proporcionar sólida interação da empresa com a universidade, por exemplo. Para Hagedoorn (1993) a parceria tecnológica consiste em um tipo de cooperação interfirmas, em que pelo menos uma parte do acordo estabelece atividades de inovação cooperada ou trocas tecnológicas entre as partes. O caráter estratégico significa que pelo menos uma das partes apresenta a expectativa de usufruir o resultado das atividades conjuntas, em determinado posicionamento de mercado no longo prazo. Para Chesnais (1996, p. 169), as alianças permitem a partilha dos altos custos de atividades de $\mathrm{P} \& \mathrm{D}$ e a troca de conhecimentos tecnológicos.

\section{Formas de Abordagem das Alianças}

Segundo Vilkamo e Keil (2003), os estudos de alianças podem ser compreendidos sob quatro dimensões distintas: as motivações que determinam sua formação; os mecanismos de controle; as questões dinâmicas relativas a processos; e os aspectos de desempenho. Vilkamo e Keil (2003) e Hakansson e Sharma (1996) ressaltam a importância do histórico do relacionamento interorganizacional para a caracterização das alianças, entre eles o entendimento sobre a existência de um ciclo de vida que compreende as etapas de formação, operacionalização e finalização, constituindo aspectos relevantes no entendimento dos estudos com enfoque processual. Neste sentido, a proposta de Ring e Van de Ven (1992), com o objetivo de compreender processualmente os relacionamentos interorganizacionais aponta um entendimento alternativo à compreensão seqüencial do ciclo de vida das interações das organizações.

Para esses autores, o processo de desenvolvimento da cooperação interorganizacional é compreendido de forma cíclica e não obrigatoriamente seqüencial, abarcando necessariamente períodos de início e término. O caráter cíclico não se deve à estabilidade alcançada no relacionamento, mas à manutenção de equilíbrio entre processos formais e informais de interação. Quando este equilíbrio é alterado, o relacionamento passa a ser ameaçado. O processo de desenvolvimento do relacionamento sob o modelo cíclico compreende três etapas, quais sejam: negociação, comprometimento e execução. De acordo com Ring e Van de Ven (1994), as relações interorganizacionais cooperativas constituem mecanismos socialmente construídos, continuamente moldados e reestruturados 
pelas ações e interpretações simbólicas das partes envolvidas. Assim como a estrutura inicial de salvaguardas estabelece o contexto de ação das partes, também as interações subseqüentes reconstroem novas estruturas de governança no relacionamento. Neste sentido, segundo Ring e Van de Ven (1994), as fases do processo de desenvolvimento dos relacionamentos interorganizacionais podem ser resumidas da seguinte forma.

(1) Negociação. Ocorre a negociação de expectativas conjuntas a respeito de motivações, de possíveis investimentos e da identificação de incertezas relativas ao relacionamento a ser desenvolvido entre as partes. Nesse estágio, o foco está associado a processos de barganha e orientação de comportamentos, à medida que as partes selecionam, abordam ou evitam parceiros alternativos, e persuadem, argumentam e pechincham sobre possíveis termos e procedimentos de um potencial relacionamento. Acompanhando esses procedimentos formais de barganha, ocorrem procedimentos psicossociais de construção de sentido ou ajustamento que levam partes independentes a entrar no relacionamento. Esforços repetidos por meio de barganha formal e construção de sentido informal são geralmente necessários para prover às partes o acesso às incertezas envolvidas, à natureza e à confiabilidade de cada parte, aos direitos e aos deveres, bem como à eficiência e à eqüidade esperada de cada contraparte.

(2) Compromisso. O comprometimento entre as partes da aliança voltadas para ações futuras ocorre por meio de contratos formais e contratos informais. Neste momento os termos e a estrutura de governança do relacionamento são estabelecidos mediante contratos relacionais formais e/ou compreendidos informalmente em 'acordos psicológicos' entre as partes. Como no estágio anterior, uma série de interações das partes é necessária para haver consentimento mútuo legitimado. Dependendo do risco percebido no negócio e da vontade das partes em basear o relacionamento na confiança, muitos desses compromissos serão alcançados informalmente. Entende-se por contratos psicológicos as expectativas e premissas comuns sobre prerrogativas e obrigações das contrapartes. Estas expectativas a respeito do que cada parte irá dar e receber no relacionamento varia em grau de explicitação, sendo que as partes geralmente estão apenas marginalmente conscientes da natureza exata dessas expectativas.

(3) Execução. Compreende a concretização de compromissos mediante a interação de papéis organizacionais e interações interpessoais. Nesta etapa, compromissos e regras são levados a efeito. As partes dão ordens aos seus subordinados, adquirem materiais, pagam montantes acordados e administram conforme as necessidades do que foi acordado. Inicialmente os comportamentos baseados em designações formais reduzem a incerteza, quando os compromissos são executados, aumentando a previsibilidade do relacionamento. A partir de uma 
série de interações, as pessoas envolvidas se tornam mais conhecidas umas das outras e se podem basear, de forma crescente, em relacionamentos interpessoais, em vez de relacionamentos baseados em papéis formais. Essas fases do processo de desenvolvimento dos relacionamentos interorganizacionais podem ser vistas na Figura 1.

\section{Figura 1: Fases do Processo de Desenvolvimento dos Relacionamentos Interorganizacionais}

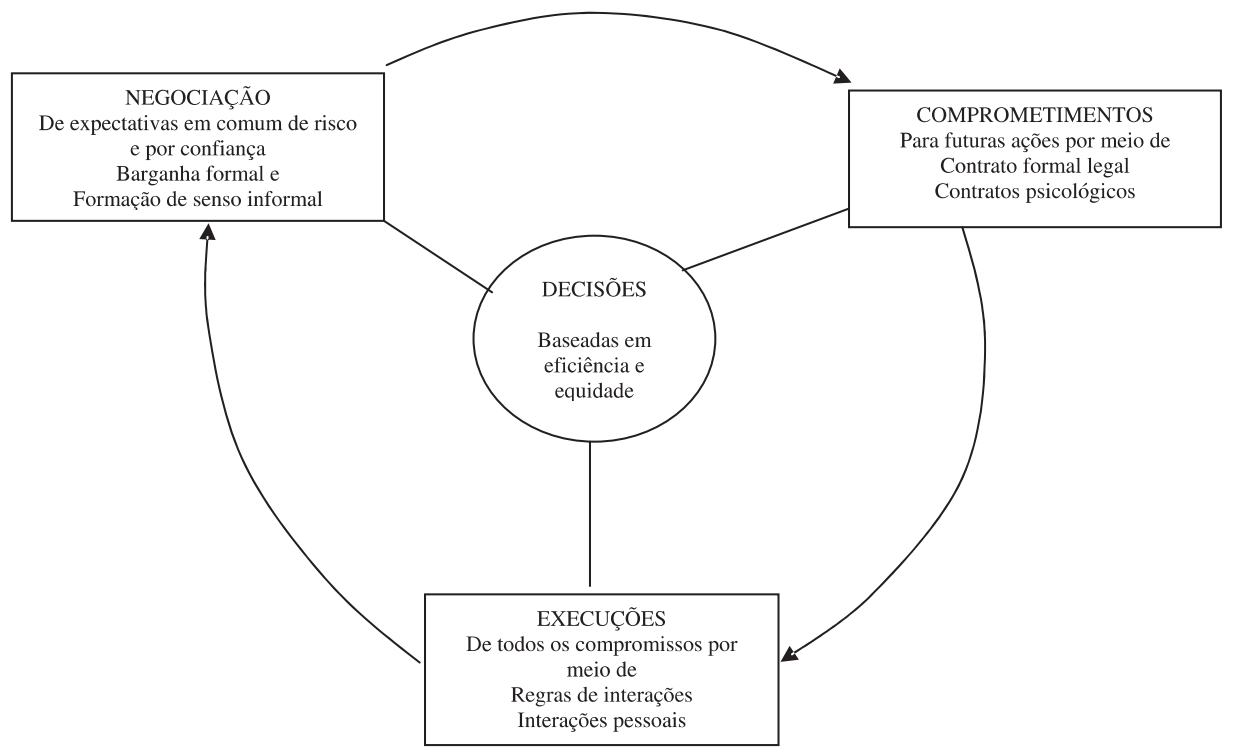

Fonte: Adaptado de Ring e Van de Ven (1994, p.08)

\section{Mecanismos de Controle}

A discussão do conceito de mecanismos de controle se insere no contexto dos aspectos relativos a questões tanto estruturais, que envolvem a regulação formal das relações, como dos aspectos processuais de cooperação, coordenação de conflitos e adaptações (Hakansson \& Sharma, 1996). Os mecanismos de controle constituem elemento instrumental das estruturas e processos de governança das relações de cooperação em alianças entre empresas.

\section{Bases para o Controle}

Os estudos relativos ao fenômeno de controle têm sua origem na estrutura interna das organizações, em que a ênfase está relacionada com a ação das 
organizações sobre os indivíduos que as compõem. Dessa forma, Etzioni (1974) e Ouchi (1979) consideram que os objetivos do controle estão associados a minimizar divergências entre organizações e seus integrantes.

Hatch (1997), por sua vez, considera que o controle pode tanto ser aplicado em indivíduos como em unidades organizacionais e organizações. $\mathrm{O}$ autor compreende que, na moderna teoria organizacional, o controle é visto como mecanismo de implementação estratégica, que pressupõe que a organização deve regular e certificar-se de que interesses divergentes não interfiram nas metas e estratégias da organização. Essa abordagem dá ênfase aos mecanismos de controle comportamental, visando garantir que interesses individuais sejam minimizados. Três perspectivas modernas de controle são distinguidas por Hatch (1997). A primeira lida com a avaliação de desempenho e retorno. Esta abordagem tem muito em comum com o modelo cibernético da Teoria Geral de Sistemas. A segunda abordagem, conhecida como teoria de agência, foi desenvolvida recentemente no contexto de comportamentos econômicos e contábeis. Esta visão focaliza o controle do comportamento de gerentes via contratos desenhados para encorajar gerentes a servir aos interesses dos proprietários da organização. A terceira teoria compara mercados, burocracias e clãs, como formas alternativas de controle organizacional, e levanta o aspecto de adoção da cultura como mecanismo de controle. $\mathrm{O}$ autor dá indícios de que o controle pode ser avaliado no nível das organizações e não apenas na relação entre indivíduos e organizações; ele propõe as categorias de controle baseadas tanto em hierarquias (burocracias) e em controles regulados por preços (mercados), quanto em fatores associados a processos de socialização e influenciados pela cultura (clã). Segundo o autor, se a transação envolve um ativo particular, isso faz com que a norma da reciprocidade e a valoração só possam ser compreendidas pelas partes envolvidas e não pelo contexto social em que se inserem.

Tais ativos podem ser identificados em processos de desenvolvimento tecnológico cooperado, em que se verifica crescente interdependência tecnológica das organizações. Nesses casos, a capacidade dos controles de mercado ou burocráticos de prever e mensurar todo o desempenho não se aplicam, de forma que passam a 77 ser adotados controles por meio de internalização de valores, adotação de elementos rituais e cerimoniais que não garantem a previsibilidade total do alcance dos resultados esperados mas atuam como influenciadores nos processos de controle.

\section{Mecanismos de Controle em Relações de Alianças}

Para Child, Faulkner e Pitkethly (2000), o controle nas relações entre empresas deve variar de acordo com o tipo de aliança empreendida; o maior ou menor uso 
de mecanismos de controle pode influenciar a confiança e o desempenho da empresa. Para Geringer e Hebert (1989), no contexto específico das alianças estratégicas do tipo joint-ventures, o conceito de controle constitui processo pelo qual uma entidade influencia, em graus variados, o comportamento e resultado de outra entidade mediante o uso do poder e da autoridade, por meio de mecanismos burocráticos, culturais e informais. Os mecanismos de controle, por sua vez, visam coordenar atividades, uso eficiente de recursos e implementação de estratégias, bem como a proteção de estratégias internas, competências tecnológicas e outros elementos pertencentes a grupos externos. Child e Faulkner (1998) indicam possíveis mecanismos de controle práticos identificados nas relações de joint-ventures no Quadro 1.

\section{Quadro 1: Tipos de Controle}

\begin{tabular}{|c|c|c|}
\hline Mecanismos de controle & Função do mecanismo & Exemplo \\
\hline Controles de entrada & $\begin{array}{l}\text { Facilita a ação em níveis de condições } \\
\text { controladas }\end{array}$ & $\begin{array}{l}\text { Transferência de preços, distribuição de } \\
\text { recursos, gestão da informação, } \\
\text { treinamento e desenvolvimento pessoal }\end{array}$ \\
\hline Controle comportamental & $\begin{array}{l}\text { Especifica o modo correto de realizar } \\
\text { o trabalho }\end{array}$ & $\begin{array}{l}\text { Políticas, planos, especificações de } \\
\text { métodos, regras e supervisão direta. }\end{array}$ \\
\hline Controle de saída & $\begin{array}{l}\text { Especifica resultados pretendidos, } \\
\text { monitoramento e premiação para seu } \\
\text { alcance }\end{array}$ & $\begin{array}{l}\text { Metas, orçamentos, reportar resultados, } \\
\text { pagamento mediante desempenho. }\end{array}$ \\
\hline Socialização de valores & Define e cria valores comuns & $\begin{array}{l}\text { Culturas organizacionais expressas por } \\
\text { meio de sistemas de crenças, rituais e } \\
\text { tradições }\end{array}$ \\
\hline Adaptação, socialização & $\begin{array}{l}\text { Torna pessoas familiares com os } \\
\text { valores e práticas de outras }\end{array}$ & $\begin{array}{l}\text { Padronização de habilidades, pressão de } \\
\text { colegas, programas de sensibilização } \\
\text { cultural }\end{array}$ \\
\hline Envolvimento pessoal & $\begin{array}{l}\text { Sinaliza o que os gerentes das } \\
\text { parcerias pensam que seja importante }\end{array}$ & $\begin{array}{l}\text { Visitas e participação pelos gerentes, } \\
\text { comunicação verbal }\end{array}$ \\
\hline Estrutura hierárquica & $\begin{array}{l}\text { Enfatiza e apóia parceiros metas das } \\
\text { alianças }\end{array}$ & $\begin{array}{l}\text { Membros da diretoria, reuniões com } \\
\text { gerentes e ações de reporte }\end{array}$ \\
\hline Estrutura lateral & $\begin{array}{l}\text { Influencia pessoas a interagir em } \\
\text { torno de limites formais }\end{array}$ & $\begin{array}{l}\text { Gatekeepers entre parceiros, equipes } \\
\text { formadas por agentes de ambos os } \\
\text { parceiros. }\end{array}$ \\
\hline
\end{tabular}

Fonte: Adaptado Child e Faulkner (1998).

Geringer e Hebert (1989) propõem a adoção da classificação dos mecanismos de controle em três diferentes grupos: mecanismos orientados pelo contexto, mecanismos orientados por conteúdo e mecanismos orientados por processo. Os mecanismos de controle orientados pelo contexto são baseados em elementos informais e culturais, sendo seu objetivo estabelecer um contexto apropriado, para que os parceiros alcancem seus objetivos. O compartilhamento de uma mesma cultura organizacional, segundo Das e Teng (1998), provê um sentido de controle, pois unifica a forma como os membros das organizações parceiras processam a informação e reagem ao ambiente, causando, assim, maior previsibilidade do comportamento dos funcionários. 
Sua verificação se pode dar por meio de processos de socialização e treinamento, os quais intensificam a interação dos funcionários das empresas, tornando-os familiarizados com a cultura organizacional de suas respectivas contrapartes. Van Marrewijk (2005) aponta que os processos de socialização se tornam relevantes, quando se considera a importância de contornar diferenças culturais, comportamentais e de expectativas em projetos cooperados, envolvendo empresas do setor público e privado. Os mecanismos orientados por conteúdo são geralmente formais, com intervenção direta de gerentes e diretores, ou ainda tipicamente burocráticos, como, por exemplo, o direito de veto ou designação de responsabilidades específicas, estando geralmente baseados em documentos formais.

Já os mecanismos orientados por processo são aqueles pelos quais as empresas exercem controle mediante processos de planejamento e tomada de decisão, como no exemplo da participação dos funcionários das parceiras no planejamento da joint-venture. Geringer e Hebert (1989) consideram que os mecanismos de controle podem ser analisados de acordo com o tipo de mecanismo adotado e o foco do controle, ou seja, sobre que tipos de atividades é exercido o controle. A classificação desses autores não restringe os controles a dimensões somente formais ou informais, permitindo a abrangência de componentes sociais, hierárquicos e com base em ações, o que se torna coerente com o fundamento do controle proposto por Ouchi (1979) que, na sua concepção, compreende que nas relações tanto fatores hierárquicos quanto de mercado e baseados em normas sociais podem exercer influência como elementos de controle.

\section{Metodologia}

A metodologia empregada para concretização da pesquisa foi proposta sobre uma base de caráter qualitativo, com o emprego da estratégia de pesquisa de estudo múltiplo de casos em profundidade. A pesquisa de caráter descritivoexploratório possui o objetivo de descrever as características de um fenômeno, qual seja, a adoção de mecanismos de controle no contexto da governança de alianças estratégicas e buscar subsídios informacionais que indiquem que fatores determinam a adoção dos mecanismos de controle, ao longo das fases do relacionamento. Sendo o objeto de estudo deste trabalho as alianças constituídas entre empresas, o nível de análise escolhido foi relacional-organizacional e a unidade de análise foram os mecanismos de controle identificados.

A estratégia de pesquisa escolhida, conseguintemente, foi o estudo múltiplo de casos, o que, segundo Collis e Hussey (2005), constitui modelo adotado em 
pesquisas de caráter descritivo e exploratório. De acordo com Yin (2001), os estudos de caso geralmente apresentam mais variáveis de interesse do que pontos de dados e, em consequiência, se baseiam em várias fontes de evidência. Os casos estudados apresentam como fonte de informação dados primários e secundários. Os dados primários compreenderam a realização de entrevista semiestruturada com dirigentes de nível estratégico das organizações responsáveis pelos processos de interação. Os dados secundários permitiram o processo de triangulação e abrangeram relatórios anuais, entrevistas, informações disponíveis no sítio eletrônico das empresas e outros boletins informativos, além de documentos contratuais, registros de atas de reuniões, normas e procedimentos, registro de comunicações entre as empresas, com a devida autorização de emissores e receptores. A predeterminação das características das fontes de informações de fontes primárias direcionou a escolha de informantes, que foram selecionados por adesão e disponibilidade em atender ao estudo. A análise de dados primários, originados das entrevistas semi-estruturadas, ocorreu por meio da técnica de análise de conteúdo de documentos e entrevistas gravadas e transcritas. Na análise de conteúdo, foi proposta a adoção de indicadores qualitativos; a técnica selecionada compreende a análise de categorização temática, de acordo com Bardin (2002).

\section{AnÁlise dos Casos}

\section{Aliança Alfa}

A empresa A é uma sociedade anônima, constituída legalmente em 2004. Foi criada para centralizar a coordenação e o desenvolvimento e produção, no Estado de Santa Catarina, de um veículo automotivo de origem nacional. O projeto e a própria empresa A tiveram como fatores motivadores de sua criação a existência de uma indústria de autopeças de importância nacional em Santa Catarina, que deseja fortalecer sua posição diante dos mercados de empresas montadores de veículos, uma vez que atualmente não há a presença de nenhuma indústria do segmento automotivo naquele Estado. A empresa B constitui uma empresa industrial catarinense especializada na produção de tubos de aço, tendo iniciado suas atividades a partir de 1947, no município de Jaraguá do Sul.

Atualmente, a empresa fornece componentes automotivos para todas as indústrias montadoras de veículos instaladas no Brasil e, recentemente, diversificou sua produção, visando atender ao mesmo mercado com componentes de maior valor agregado. As atividades de desenvolvimento tecnológico da empresa compreendem a concepção de soluções customizadas para o setor automotivo e 
atividades de pesquisa e desenvolvimento, de forma cooperada com laboratórios e centros de pesquisa universitários, entre eles laboratórios de pesquisa do departamento de Engenharia Mecânica da Universidade Federal de Santa Catarina, UFSC, e da Pontifícia Universidade Católica do Paraná, PUCPR. O objetivo da parceria, confirmado pelos entrevistados das duas empresas, consiste na consolidação de um projeto de veículo automotivo com características inovadoras, baseadas na adoção de estrutura tubular para o nicho específico de veículos utilitários, e a sua posterior produção em série, a partir de uma cadeia de fornecimento que envolva outras empresas de autopeças de Santa Catarina. O desenvolvimento do projeto de engenharia do veículo exigiu a interação direta da equipe de engenharia contratada pela empresa A com a equipe de engenharia da empresa $\mathrm{B}$, que colocou à disposição do projeto sua equipe de engenharia e toda a sua tecnologia de fabricação de tubos, corte, dobra e solda por meio de máquinas de comando numérico e robótica.

A elaboração dos modelos funcionais (protótipos) foi realizada também de forma cooperada; a operacionalização esteve sob responsabilidade da empresa B e a avaliação e coordenação destas atividades sob responsabilidade compartilhada das duas empresas. Outro conjunto de elementos produzidos sob responsabilidade conjunta foi o ferramental que compreende os instrumentos de manufatura das peças do chassi e que são imprescindíveis para posterior reprodução do produto. A realização destas atividades envolveu etapas de negociação, comprometimento e execução de atividades, que foram identificadas ao longo do tempo, de acordo com a exemplificação do Quadro 2 abaixo.

\section{Quadro 2: Identificação das Fases do Relacionamento Empresa A - Empresa B}

\begin{tabular}{|c|c|c|c|c|c|c|c|}
\hline Período & 2001 & 2002 & 2003 & 2004 & \multicolumn{2}{|c|}{$2005 / 1$} & $2005 / 2$ \\
\hline \multirow{2}{*}{ Fases } & N1 & N2 & C1 & & N3 & \multirow{2}{*}{\multicolumn{2}{|c|}{$\begin{array}{l}\mathrm{C} 2 \\
\mathrm{E} 2\end{array}$}} \\
\hline & & E1 & & & & & \\
\hline \multicolumn{4}{|c|}{$\begin{array}{l}\mathrm{N}_{1}=1^{\mathrm{a}} \text { negociação, } \\
\mathrm{N}_{2}=2^{\mathrm{a}} \text { negociação, } \\
\mathrm{N}_{3}=3^{\mathrm{a}} \text { negociação, }\end{array}$} & \multicolumn{4}{|c|}{$\begin{aligned} \mathrm{C}_{1} & =1^{\circ} \text { comprometimento } \\
\mathrm{C}_{2} & =2^{\circ} \text { comprometimento } \\
\mathrm{E}_{1} & =1^{\mathrm{a}} \text { execução, } \\
\mathrm{E}_{2} & =2^{\mathrm{a}} \text { execução }\end{aligned}$} \\
\hline
\end{tabular}

\section{Aliança Beta}

A empresa $\mathrm{C}$ é uma empresa pertencente a um grupo multinacional, com atuação na produção, pesquisa e comercialização de compressores elétricos. Passou a produzir compressores no ano de 1971. Em 1983 montou seu primeiro grupo de pesquisa, preocupado tanto com a pesquisa básica quanto com a pesquisa aplicada, em cooperação com a Universidade Federal de Santa 
Catarina, em perspectiva de longo prazo e investindo em modelos de simulação, com o objetivo de compreender o funcionamento teórico de compressor. Atualmente a empresa possui plantas de produção instaladas no Brasil, China, Eslováquia e Itália. A empresa D é uma organização com $100 \%$ de seu capital nacional; suas atividades foram iniciadas em 1939. Possui plantas instaladas, no Brasil, Argentina, Alemanha e Hungria, e escritórios nos EUA, Reino Unido, Itália, Áustria e Austrália. A empresa atua no setor de autopeças, mais especificamente no desenvolvimento e fabricação de equipamentos de vedação, de mangueiras e juntas. Possui três grandes direcionamentos de suas atividades: a pesquisa tecnológica, o desenvolvimento de soluções funcionais para os seus clientes e a produção industrial. O processo de pesquisa e desenvolvimento (P\&D) tecnológico da empresa é orientado pela identificação das necessidades do cliente e pela análise de oportunidades de melhoria de processos.

A área de P\&D possui 4 linhas estratégicas: o desenvolvimento de pesquisa, em projetos de curto e de longo prazo; o atendimento das expectativas do cliente, visando tornar-se um leader-source; a geração de inovação de desruptura; e a redução de custo no fornecimento a clientes. De acordo com os entrevistados, duas frentes principais de atividades passaram a ocorrer entre as duas empresas, a partir do final do ano de 2004. A primeira série de atividades, segundo o entrevistado da empresa $\mathrm{D}$, foi motivada por seu interesse em obter informações a respeito de instrumentos de gestão tecnológica, que foram apresentados pela equipe da empresa $\mathrm{C}$, em eventos relativos ao tema de inovação na indústria. Para a empresa $\mathrm{C}$, sua motivação adveio de sua busca de novos parceiros não concorrentes para o financiamento de pesquisas de materiais comuns à cadeia de suprimentos das duas empresas. $\mathrm{O}$ segundo conjunto de atividades teve como motivação inicial o interesse daempresa $\mathrm{C}$, que necessitava identificar empresas que pudessem realizar o desenvolvimento de aplicações para a sua nova linha de compressores, suprindo sua demanda de materiais com características de vedação de alta resistência. A caracterização do ciclo do relacionamento entre as duas empresas é exemplificado de acordo com o Quadro 3.

\section{Quadro 3: Identificação das Fases do Relacionamento entre a Empresa C e a Empresa D}

\begin{tabular}{|c|c|c|c|c|c|}
\hline \multicolumn{2}{|c|}{ Períodos } & $2004 / 02$ & $2005 / 01$ & \multicolumn{2}{|c|}{$2005 / 02$} \\
\hline \multicolumn{2}{|c|}{ Troca de informações e cooperação sobre pesquisa } & N1 & $\mathrm{C} 1$ & $\mathrm{~N} 2$ & $\mathrm{C} 2$ \\
\hline \multicolumn{2}{|c|}{ Atividades de desenvolvimento } & Nd1 & $\mathrm{Cd} 1$ & \multicolumn{2}{|c|}{ Ed1 } \\
\hline $\begin{array}{l}\mathrm{N}_{1}=1^{\mathrm{a}} \text { negociação, } \\
\mathrm{C}=\text { comprometimento, } \\
\mathrm{N}_{2}=2^{\mathrm{a}} \text { negociação, }\end{array}$ & \multicolumn{5}{|c|}{$\begin{array}{l}\mathrm{C}_{2}=2^{\circ} \text { comprometimento, } \\
\mathrm{N}_{1 \mathrm{~d}}=\text { negociação de atividades de desenvolvimento, } \\
\mathrm{C}_{\mathrm{d} 1}=\text { comprometimento de atividades de desenvolvimento, } \\
\mathrm{E}_{\mathrm{d} 1}=\text { execução de atividades de desenvolvimento }\end{array}$} \\
\hline
\end{tabular}




\section{Aliança Gama}

A empresa E foi fundada em 1938, em Joinville. Seu negócio tem como foco atividades de fundição, voltadas para a produção de peças para sistemas de propulsão, freio, transmissão, direção, eixo e suspensão direcionados ao setor automotivo e outras indústrias do setor metal-mecânico. Em 1963 uma segunda unidade de fundição foi instalada, para produzir peças automotivas, e em 1972 foi criado o primeiro centro de pesquisa, em parceria com a Escola Politécnica da Universidade de São Paulo. A empresa E passou a enfocar a fundição, que é seu negócio central; com isso ampliou suas exportações. Atualmente posiciona-se entre as cinco maiores fundições do mundo, atendendo primordialmente o segmento automotivo.

A empresa possui capacidade para produzir 500 mil toneladas anuais de peças de ferro fundido, em dois parques fabris: um em Joinville e outro em Mauá, no Estado de São Paulo. Metade de sua produção atual é exportada para mais de 40 países e suas atividades de desenvolvimento estão concentradas em engenharia de produtos, engenharia metalúrgica e engenharia da qualidade. A empresa F é uma empresa de origem sueca, que mantém escritórios na Suécia, Chicago e Londres, e desenvolve, produz e fornece tanto sistemas de controle de processos produtivos como conhecimento tecnológico de engenharia para a produção, em larga escala, de tecnologia de ferro fundido vermicular (Compacted Graphite Iron - CGI). A empresa foi fundada em 1983, quando registrou sua primeira patente. De 1984 a 1991, desenvolveu pesquisa básica para a solidificação do comportamento do CGI; o desenvolvimento desta tecnologia continuou ocorrendo entre os anos de 1990 a 2000. Nesta etapa, segundo o entrevistado, atividades de pesquisa básica e P\&D teriam ocorrido para consolidação da tecnologia de ferro fundido vermicular e do sistema computacional para sua produção. No ano de 1996, com uma tecnologia forte, a empresa iniciou a busca de parceiros que complementassem a solução fornecida pelo CGI, mediante a inclusão, no desenvolvimento da tecnologia das especificidades de cada área de atuação do setor metal mecânico.

As atividades desenvolvidas de forma cooperada entre as duas empresas tiveram por objetivo inicialmente o aperfeiçoamento da tecnologia de ferro vermicular de alta usinabilidade e a identificação do seu potencial mercado. Para tais ações utilizou-se o conhecimento desenvolvido pela empresa F; a empresa E, durante o período de 1996 a 2000, contribuiu com conhecimentos que aperfeiçoaram os processos de produção de blocos e cabeçotes, adotando a tecnologia de ferro fundido vermicular para o mercado automotivo. A primeira produção que utilizou a tecnologia de CGI ocorreu em 2000; deste período a 2004, a empresa E, com a cooperação da empresa F, realizou a 
produção e teste de protótipos para viabilização comercial de componentes automotivos, complementando, assim, a disponibilidade das soluções em CGI para o mercado de peças de veículos. Atualmente, a empresa E utiliza a tecnologia CGI para produzir peças para seus clientes, enquanto a empresa $\mathrm{F}$ comercializa a tecnologia e o sistema computacional para produção do CGI. O Quadro 4 exemplifica a identificação das etapas do relacionamento, que abrangem as etapas de negociação, comprometimento e execução das atividades cooperadas.

\section{Quadro 4: Identificação das Fases do Relacionamento entre a Empresa $E$ e a Empresa $F$}

\begin{tabular}{|c|c|c|c|c|c|c|c|c|c|c|}
\hline Períodos & $1996 / 1$ & $1996 / 2$ & 1997 & 1998 & 1999 & 2000 & 2001 & 2002 & 2003 & 2004 \\
\hline Fases & N1 & $\mathrm{C} 1$ & \multicolumn{2}{|c|}{ E1 } & $\mathrm{C} 2$ & \multicolumn{5}{|c|}{ E2 } \\
\hline \multicolumn{5}{|c|}{$\begin{array}{l}\mathrm{N}_{1}=1^{\mathrm{a}} \text { negociação } \\
\mathrm{C}_{1}=1^{\circ} \text { comprometimento } \\
\mathrm{E}_{1}=1^{\mathrm{a}} \text { execução }\end{array}$} & \multicolumn{4}{|c|}{$\begin{array}{l}\mathrm{C}_{2}=2^{\circ} \text { comprometimento } \\
\mathrm{E}_{2}=2^{\mathrm{a}} \text { execução }\end{array}$} & & \\
\hline
\end{tabular}

\section{Mecanismos de Controle x Alianças x Foco x Fases}

Os focos que caracterizaram os instrumentos adotados em cada uma das etapas dos relacionamentos são identificados no Quadro 5. Se em um primeiro momento a literatura considera que a principal preocupação dos instrumentos de controle, em alianças estratégicas, diz respeito à regulação dos conteúdos, pode-se verificar que um conjunto de outros fatores também faz parte das preocupações de ações tomadas nas relações, o que tentaremos esclarecer neste momento, entre eles a preocupação com a gestão do próprio relacionamento. Na etapa caracterizada pela negociação, ao longo das três alianças, tanto as reuniões quanto a busca de informações junto a terceiros constituíram procedimentos que auxiliaram as empresas a conhecer as reais capacidades dos parceiros e a obter informações sobre as referidas contrapartes.

A busca de informação sobre parceiros constitui, segundo Etzioni (1974) e Ouchi (1979), componentes complementares aos controles que visam à minimização de outros instrumentos regulatórios. As reuniões serviram ainda, junto com as comunicações a distância, para determinar condições do relacionamento, ou seja, para a gestão do andamento do relacionamento. $\mathrm{O}$ agendamento de reuniões, o local para sua execução, a pauta das reuniões e que recursos de telecomunicação passariam a ser adotados para a troca de informações estratégicas, isso abrangeu o conteúdo das discussões ocorridas a distância, enquanto nas reuniões a definição de que tipos de projetos seriam discutidos, quais as equipes envolvidas, bem como seus responsáveis constituíram o foco de tais processos. 
A definição de cada empresa a respeito das pessoas responsáveis pela interação com a contraparte, o agente concentrador das decisões e como ocorre o fluxo de informações entre uma equipe e outra também se tornaram alvos das preocupações das empresas, visando regular e orientar o andamento das relações. Ainda no contexto da etapa de negociação, o processo de monitoramento, por parte dos níveis hierárquicos superiores das empresas envolvidas, também constituiu fator considerado pelas empresas.

Para acompanhar a evolução das tratativas, foi verificado, em certos casos, tanto a participação direta da direção tecnológica de uma empresa, quanto a comunicação posterior na forma de relatório de ações para a direção tecnológica da empresa parceira. A preocupação com a proteção de informações estratégicas das empresas foi evidenciada nesta etapa do relacionamento (Aliança Beta e Gama). As empresas adotaram rotinas de não divulgação ao longo das discussões sobre informações sigilosas.

Na etapa caracterizada pela definição de expectativas formais e informais entre as partes, os processos e componentes que proporcionaram a identificação de acordos realizados foram identificados como instrumentos associados à coordenação e controle. Tanto as reuniões quanto a adoção de cartas de intenções, termos de confidencialidade e contratos direcionaram a criação de expectativas. A assinaturado do termo de confidencialidade passou a determinar quais as expectativas das partes, quanto ao tratamento dado às informações transacionadas entre as partes, o seu conteúdo, bem como o prazo de vigência destas condições. O contrato, por sua vez, verificado apenas na aliança Gama, abrangeu a regulação das expectativas sobre os seguintes itens: destinação dos resultados do projeto, o atendimento aos interesses de cada parte, a definição de responsabilidades, a distribuição de custos, o cumprimento do cronograma, a determinação da propriedade do objeto da atividade de interação, o alcance de objetivos predeterminados e o tipo de informação tecnológica colocada à disposição de cada parceiro.

$\mathrm{Na}$ ausência dos contratos, alguns dos elementos regulados pelos contratos foram acordados informalmente ou com a adoção da formalização por meio de atas das reuniões entre os responsáveis de cada uma das empresas. Novamente nesta etapa foi identificada a preocupação com a proteção de informações estratégicas, ao longo das interações. A fase do relacionamento caracterizada pela maior interação das partes (execução de atividades conjuntas) abrangeu uma série de elementos que influenciaram a regulação dos relacionamentos de alianças.

As reuniões, visitas, comunicações a distância, bem como a utilização de 
softwares de gestão de projetos e adoção de cronogramas serviram como elementos que auxiliaram no processo de monitoramento de resultados e prazos relativos à execução de atividades, os quais foram utilizados extensamente por todas as empresas. Na etapa de execução, nova delegação de responsabilidades ocorreu para a definição não dos gestores dos relacionamentos mas dos executores de atividades cooperadas. Esta delegação foi acompanhada da transmissão de atribuições e informações regulatórias constantes em instrumentos formais, como contratos, mas eles não estavam disponíveis para estas equipes.

Um componente diferenciado de controle, nesta etapa, aplicado entre as empresas da aliança Alfa, teve como foco a mudança de comportamento de funcionários quanto ao seu comprometimento com o projeto, sendo adotadas conversas informais para sua aplicação. Outro elemento singular desta parceria foi a proteção de informações não associadas ao conteúdo tecnológico transacionado, mas relativas a mudanças internas, que visavam não gerar desconfianças quanto ao comprometimento das empresas parceiras. Em função de condições não previstas ocorreu ainda a adoção de instrumentos regulatórios de custeio de atividades, que passaram a ser adotados na interação da empresa $\mathrm{A}$ com a empresa B.

\section{Influenciadores dos Mecanismos de Controle}

Considerando a proposta do trabalho de investigar os mecanismos de controle ao longo do relacionamento, cumpre verificar se existe alguma relação entre as fases do processo de interação e o momento em que os entrevistados apontam a emergência dos fatores influencienciadores. Preocupações como a avaliação do objeto do relacionamento, a credibilidade do parceiro, o tamanho e origem da empresa parceira, bem como a avaliação da sua reputação e a avaliação dos indivíduos que compõem a parceria foram apontados como fatores que interferem no momento em que se busca conhecer o parceiro, o que caracteriza a fase de negociação, de acordo com Ring e Van de Ven (1994). No entanto a reputação do parceiro, tanto no nível organizacional como dos indivíduos, segundo os entrevistados, baseiam-se nas informações obtidas tanto por terceiros, na fase de negociação, como em interações anteriores, o que foi evidenciado pela preocupação em iniciar o relacionamento sobre projetos de conteúdo envolvendo menores riscos, segundo os entrevistados da aliança Beta. Neste sentido, a busca de tais informações se manifesta tanto nas fases de negociação como interação ao longo das atividades de execução. Ao longo da fase de execução, a preocupação em evitar a divulgação de problemas internos enfrentados pela empresa B (aliança Alfa) influenciou as atividades de monitoramento e controle de atividades, à medida 
que a ocultação de informações impediu o acompanhamento do projeto pela empresa parceira, assim como o próprio andamento das atividades. Entre os influenciadores identificados na fase de comprometimento, o entrevistado da empresa A apontou tanto a falta de experiência na realização de processos de cooperação como o forte laço de confiança e amizade com o dirigente da empresa parceira (anterior ao relacionamento), como determinante na limitação de instrumentos de coordenação e controle adotados, o que foi evidenciada nesta fase em que se demandou das empresas a apresentação do detalhamento dos acordos formais.

Ao contrário do posicionamento de Child (1999), que coloca a empatia como elemento constitutivo da confiança em estágios mais avançados de um relacionamento, no caso da aliança entre as empresas A e B a confiança interpessoal influenciou a configuração do relacionamento em fases posteriores. Na fase de comprometimento, foi considerado influenciador pela aliança Beta e Gama o papel da equipe técnica e da jurídica. Enquanto esta última procurou detalhar em grau máximo as cláusulas de acordos formais e a identificação de riscos potenciais dos relacionamentos, as equipes técnicas enfatizaram a flexibilização dos instrumentos, visando à possibilidade de não restringir as atividades de desenvolvimento conjunto. A busca pelo conhecimento das expectativas do parceiro, interesses sobre a cooperação, bem como sobre o uso das informações transacionadas entre as partes, foi apontado pelos entrevistados das alianças Beta e Gama como razão para a proteção de informações e reuniões entre as empresas ao longo de todo o relacionamento. Da mesma forma, a B, ao verificar diferenças de expectativas durante a execução, buscou novos instrumentos de regulação, como o controle cooperado de custos. Evidencia-se, portanto, ao longo de todas as fases do relacionamento, a preocupação dos entrevistados com as expectativas das partes e a previsibilidade de seu comportamento, conforme proposto por Das e Teng (1998). 


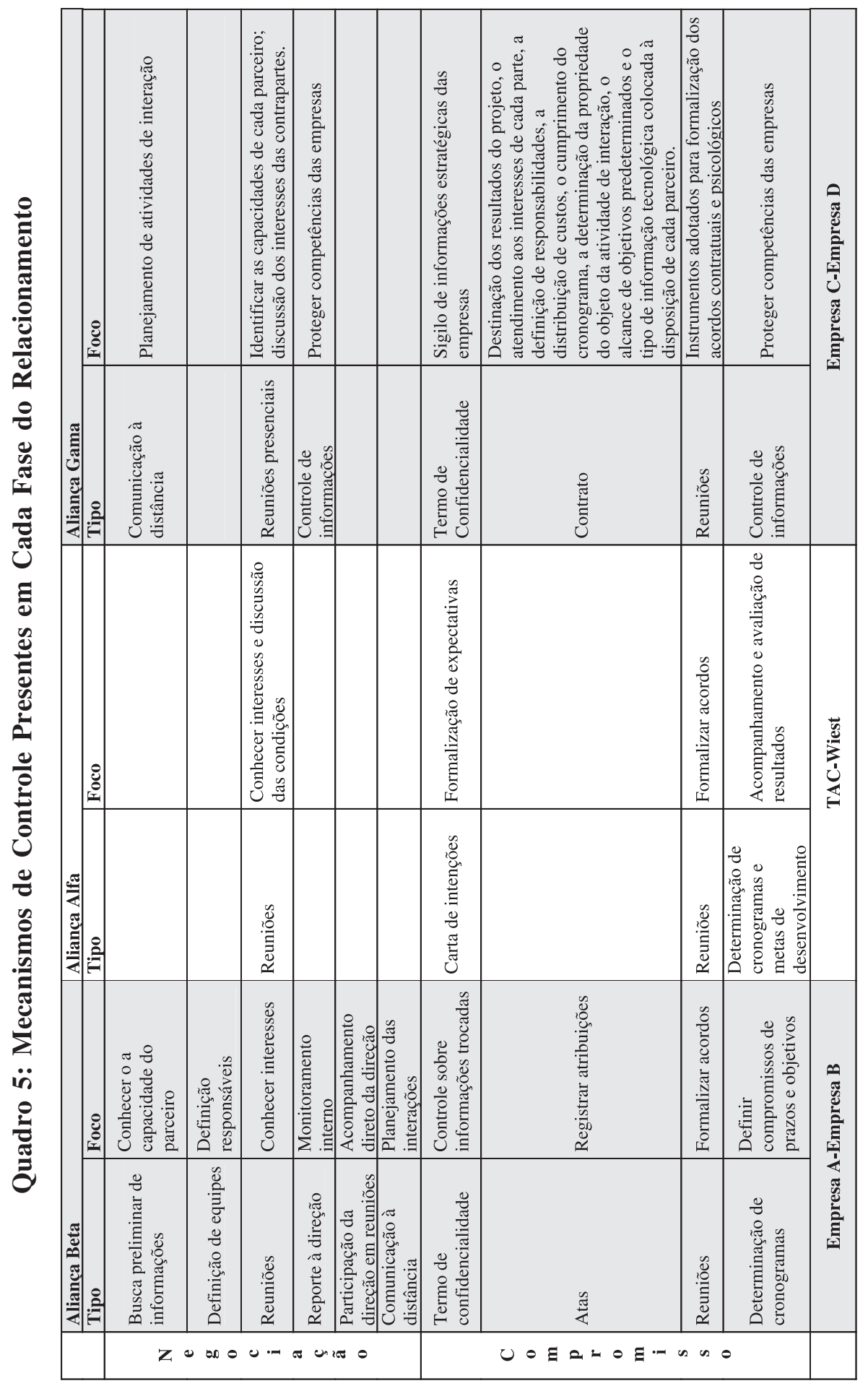




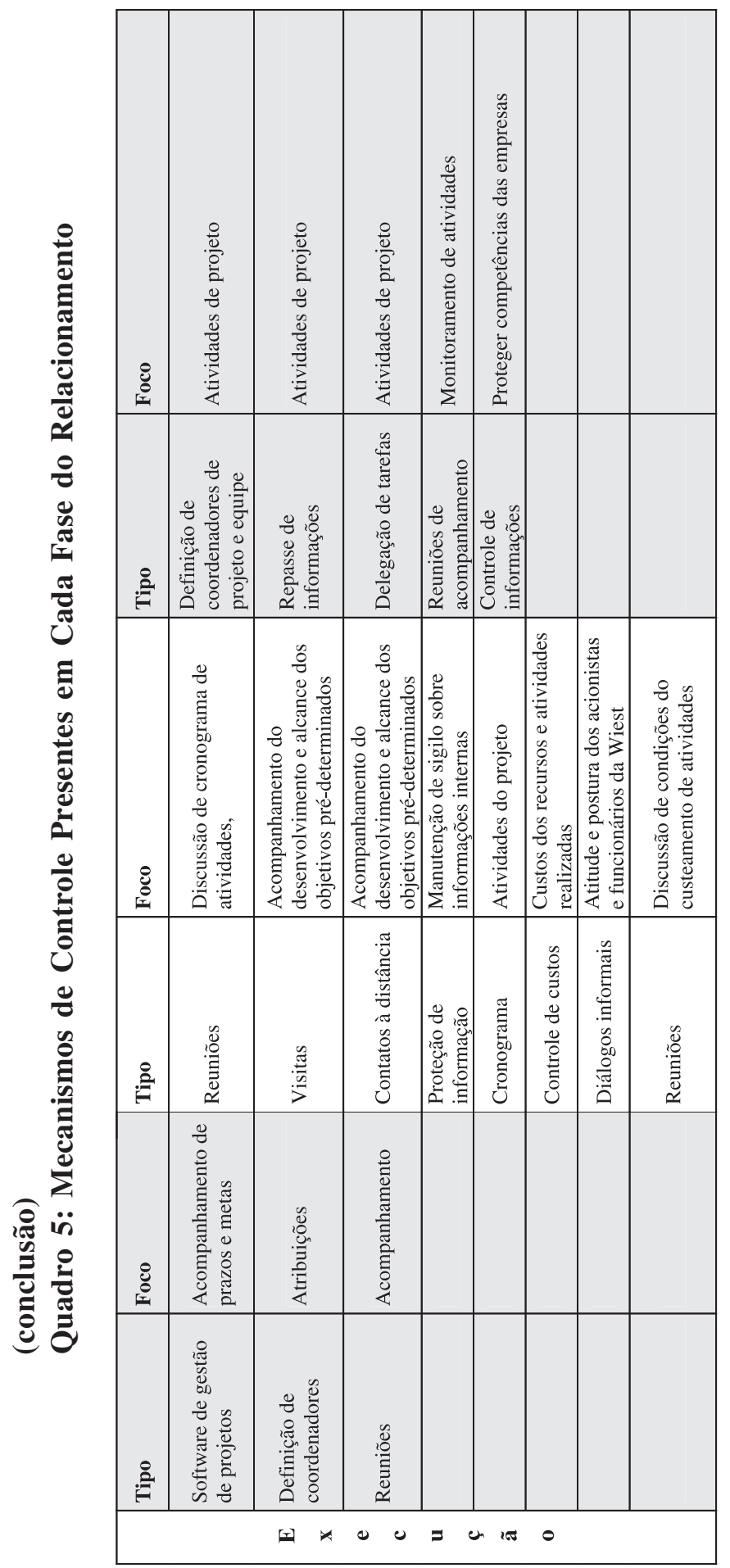




\section{Considerações Finais}

Entre os resultados alcançados pelo estudo foi verificado que todos os casos representam relações de cooperação voltadas para atividades de desenvolvimento tecnológico, sem a participação acionária direta entre as empresas, caracterizadas por desenvolvimentos conjuntos, trocas tecnológicas e até mesmo relações de cliente fornecedor. A análise dos dados permitiu a identificação de mecanismos de controle ao longo das fases verificadas nos relacionamentos estudados. Quanto à caracterização específica das fases dos relacionamentos em cada uma das alianças, comprovou-se a observação de Ring e Van de Ven (1994): as fases do relacionamento podem ocorrer de forma recorrente e de forma não necessariamente seqüencial.

A particularização da ocorrência dessas fases teria ocorrido em função de vários fatores, como o conteúdo da interação, as ações das partes sobre o relacionamento e os objetivos e expectativas. Alguns dos mecanismos de controle identificados foram verificados de forma particular em determinada fase da interação ou em uma aliança exclusivamente, enquanto outros mecanismos foram notados em mais de um caso ao longo de várias das etapas de interação. Desta forma, puderam ser identificados tanto procedimentos formais como instrumentos contratuais, até a adoção de rotinas associadas à gestão eficiente dos relacionamentos e dos interesses das organizações participantes.

Foi verificado neste contexto que tais instrumentos podem variar ao longo de cada uma das etapas do relacionamento, de acordo com seu foco de atuação. O estudo permitiu ainda observar que tais instrumentos não estão atrelados apenas à proteção dos recursos transacionados, mas também à gestão do relacionamento, o que pode ser comprovado pela preocupação das empresas em garantir que a confiança e o comprometimento de sua contraparte não seja abalada, em função das dificuldades internas vivenciadas pela empresa parceira. A identificação do foco dos mecanismos de controle adotados também pode ser verificada, evidenciando, assim, o conteúdo dos controles e os objetivos das empresas com a sua adoção.

Além disso, foi possível estabelecer um levantamento inicial dos fatores influenciadores na adoção de mecanismos de controle. Sob a perspectiva de análise das transações entre as empresas nos casos de alianças, o presente estudo concentrou-se na análise das formas de interação mais flexíveis em que, em alguns casos, o processo de formalização não foi nem mesmo completado; no entanto, mesmo com a questão difusa da caracterização das estruturas de governança das alianças, já nas fases preliminares dos três relacionamentos, a interação constitui uma realidade, o que lhe garante estrutura de gestão.

A determinação da unidade e do nível de análise, bem como a delimitação do nível 
e origem dos informantes têm origem nas recomendações propostas pela literatura, quanto ao cuidado que demandam estudos relativos à interação (Faulkner \& De Rond, 2000). A preocupação em adotar um nível de análise específico, concentrando a origem das informações nos dirigentes estratégicos responsáveis por tais relacionamentos, bem como tendo a possibilidade de ouvir as partes de ambas as empresas, constituiu fator determinante para a verificação dos dados coletados.

O estudo realizado permitiu ainda identificar novas possibilidades de pesquisa relativas aos mecanismos de controle adotados nos relacionamentos e à gestão de alianças. Nesse sentido, foram identificados os fatores influenciadores na configuração dos mecanismos de controle. Os entrevistados apontaram como influenciadores tanto fatores associados às características e expectativas dos indivíduos, como fatores associados às características das organizações e ao contexto em que estão insertas. Tais influenciadores indicam que, além de se considerar fatores relativos ao conteúdo tecnológico e aos segmentos da indústria como determinantes dos mecanismos de controle adotados em relacionamentos, deve-se verificar o microuniverso dos agentes que interagem e a dinâmica de tais relacionamentos.

O estudo da cooperação voltada para atividades de desenvolvimento tecnológico no Brasil pode evoluir sob muitos aspectos. Alguns passos foram dados recentemente, a partir da iniciativa do IBGE e MCT, por meio da pesquisa PINTEC 2004 (IBGE, 2005), que permitiu mapear o comportamento de atividades inovadoras no país por parte da iniciativa privada. Considerando que os processos de desenvolvimento tecnológico e a geração de atividades inovativas compreendem uma rede de agentes com graus variados de interação, envolvendo universidades, governos e iniciativa privada (Segatto-Mendes \& Sbragia, 2002), novos estudos relativos à gestão de processos de cooperação passam a ser demandados, para que tais fenômenos sejam regulados de forma eficiente.

\section{Artigo recebido em 02.10.2005. Aprovado em 18.12.2005.}

\section{REFERÊNCIAS BibliográficAs}

Baêta, A. M. C., \&

Silva, R. M. N. da. (2002)

Glossário dinâmico de termos na área de tecnópoles, parques tecnológicos e incubadoras de empresas. Recuperado em 20 dezembro, 2005, de http:// www.anprotec.org.br/glossario
Bardin, L. (2002).

Análise de conteúdo (pp. 46-145). (L. A. Reto \& A. Pinheiro, Trad.). Lisboa: Edições 70. (Obra original publicada em 1977). 
Castells, M. (2003). A sociedade em rede - a era da informação: economia, sociedade e cultura (Vol. 1, pp. 220-221). São Paulo: Paz e Terra.

Chesnais, F. (1996). A mundialização do capital. São Paulo: Ed. Xamã.

\section{Child, J. (1999).}

Confiança e alianças estratégicas internacionais: o caso das jointventures sino-estrangeiras. In S. B. Rodrigues (Org.). Competitividade, alianças estratégicas e Gerência Internacional (pp. 151-182). São Paulo: Ed. Atlas.

Child, J.,

Faulkner, D. O., \&

Pitkethly, R. (2000).

National differences in acquisition integration. In D. O. Faulkner \& M. Rond (Eds.). Cooperative strategy: economic, business and organizational studies (pp. 283-306). Cornwall: Oxford.

Child, F. \&

Faulkner, D. (1998).

Strategies of cooperation: managing alliances, networks, and joint ventures. Oxford: Oxford University Press.

Collis, J., \&

Hussey, R. (2005).

Pesquisa em administração: um guia prático para alunos de graduação $e$ pós-graduação (2a ed.). (L. Simonini, Trad.). Porto Alegre: Bookman. (Obra original publicada em 1997).
Das, T. K., \&

Teng, B. S. (1998).

Between trust and control: developing confidence in partner cooperation in alliances. The Academy of Management Review, 23(3), 491-512.

Etzioni, A. (1974).

Organizacões modernas (4a ed.). São Paulo: Ed. Pioneira.

Faulkner, D. O., \&

Rond, M. (2000).

Concluding thoughts and future directions. In D. O. Faulkner \& M. Rond (Eds.). Cooperative strategy: economic, business and organizational studies (pp. 375-378). Cornwall: Oxford.

Geringer, J., \&

Hebert, L. (1989).

Control and perfomance of international joint ventures. Journal of Interantional Business Studies, 20(2) 235-254.

Hakansson, H., \&

Sharma, D. D. (1996).

Strategic alliances in a network perspective. In D. Iacobucci (Ed.). Marketing Networks (pp. 108-124). London: SAGE.

Hatch, M. J. (1997).

Organization theory: modern, symbolic and postmodern perspectives. New York: Oxford University Press.

Hall, R. H. (2004).

Organizações - estruturas, processos e resultados (8a ed., pp.191-222). São Paulo: Pearson/Prentice Hall. 
Hagedoorn, J. (1993).

Understanding the rationale of strategic technology partnering: interorganizational modes of cooperation and sectoral differences. Strategic Management Journal, 14(5), 371-385.

Hagedoorn, J. (1990)

Organizational modes of inter-firm cooperation and technology transfer. Technovation, 10(1), 17-30.

Instituto Brasileiro de Geografia e Estatística - IBGE (2005).

Pesquisa PINTEC 2004. Recuperado em 12 outubro, 2005, de http:// www.ibge.gov.br

Klotzle, M. C. (2002).

Alianças estratégicas: conceito e teoria. Revista de Administração Contemporânea, 6(1), 85-104.

Ouchi, W. G. A. (1979).

A conceptual framework of the design of organizational control mechanisms. Management Science, 25(9), 833-848.

Ring, P. S., \&

Van de Ven, A. H. (1992).

Structuring cooperative relationships between organizations. Strategic Management Journal, 13(7), 483-498.
Ring, P. S.,

Van de Ven, A. H. (1994).

Developmental processes of cooperative interorganizational relationships. The Academy of Management Review, 19(1), 90-118.

Rodrigues, I. P. F., \&

Carvalho, A. O. (1991).

Dimensões e complexidade da gerência tecnológica. Revista de Administração de Empresas, 31(2), 83-89.

Segatto-Mendes, A. P., \&

Sbragia, R. (2002).

O processo de cooperação universidade-empresa em universidades brasileiras. Revista de Administração, 37(4), 58-71.

Van Marrewijk, A. (2005).

Strategies of cooperation: control and commitment in mega-projects. M@n@gement, 8(4),89-104.

Vilkamo, T., \&

Keil, T. (2003)

Strategic technology partnering in high-velocity environments lessons from a case study. Technovation, 23(3), 193-204.

Yin, R. K. (2001).

Estudo de caso planejamento e métodos (2a ed.). Porto Alegre: Ed. Bookman. 